\title{
DISCLAIMER
}

This document was prepared as an account of work sponsored by the United States Government. Neither the United States Government nor any agency thereof, nor The Regents of the University of California, nor any of their employees, makes any warranty, express or implied, or assumes any legal liability or responsibility for the accuracy, completeness, or usefulness of any information, apparatus, product, or process disclosed, or represents that its use would not infringe privately owned rights. Reference herein to any specific commercial product, process, or service by its trade name, trademark, manufacturer, or otherwise, does not necessarily constitute or imply its endorsement, recommendation, or favoring by the United States Govermment or any agency thereof, or The Regents of the University of California. The views and opinions of authors expressed herein do not necessarily state or reflect those of the United States Government or any agency thereof or The Regents of the University of California and shall not be used for advertising or product endorsement purposes.

Lawrence Berkeley Laboratory is an equal opportunity employer. 
LBL- -29819

DE92 000850

Magnetic Field in the End Region of the SSC Quadrupole Magnet*

S. Caspi, M. Helm, and L.J. Laslett

Lawrence Berkeley Laboratory

University of California

Berkeley, California 94720

June, 1991

*This work was supported by the Director, Office of Energy Research, Office of High Energy and Nuclear Physics, Division of High Energy Physics, of the U.S. Department of Energy under Contract No. DE-AC03-76SF00098.
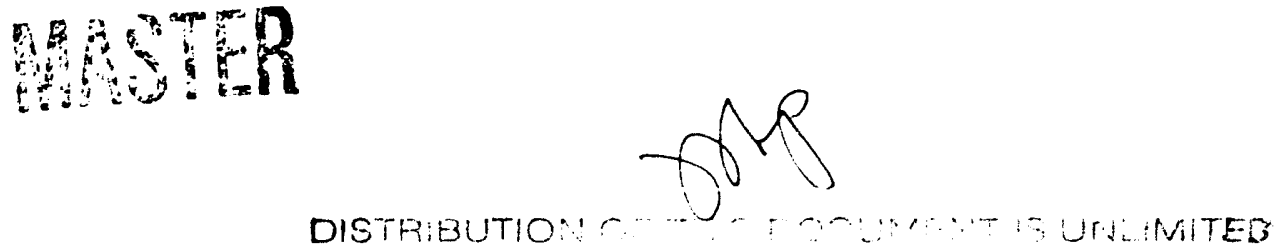


\section{Magnetic Field in the End Region of the SSC Quadrupole Magnet*}

\author{
S. Caspi, M. Helm, and L. J. Laslett \\ Lawrence Berkeley Laboratory \\ University of Califomia \\ Berkeley, CA 94720
}

\begin{abstract}
Recent advances in methods of computing magnetic fields have made it possible to study the field in the end region of the SSC quadrupole magnet in detall. The placement of conductor in the straight section, away from the ends, was designed to produce a practically pure quadrupole field in the two-dimensional sense. The ends of the colls were designed to produce a practically pure quadrupole field in the integral sense using a method that ignores the presence of the iron yoke. Subsequently, the effect of the presence of the yoke on the fieid was analyzed. The paper presents the end configuration together with the computed integrated multipole components, local multipole components, and local fleld components. A comparison with measurements is included.
\end{abstract}

\section{INTRODUCTION}

Recently, the first full scale R\&D quadrupole, magnet for the SSC was successfully tested at our laboratory. The $5 \mathrm{~m}$ long magnet is the first in a series of 6 such magnets to be built and tested in the next 12 months. The two layer 40 $\mathrm{mm}$ bore magnet with 21 turns per octant and $18 \mathrm{~mm}$ Aluminum collars, has an operating gradient of $214 \mathrm{~T} / \mathrm{m}$ at $6500 \mathrm{~A}$, systematic multipoles less than 0.04 units and a negligible iron saturation effect $[1,2]$. Made from 1.8:1 cu/sc 30 strand cable with $2750 \mathrm{~A} / \mathrm{mm}^{2}$ at $5 \mathrm{~T}, 4.2 \mathrm{~K}$, the magnet is expected to reach short sample performance at $7740 \mathrm{~A}$. Although the quad is dominated by its length some special attention was given to its "end" design.

\section{THE "END" GEOMETRY}

The cable layout in the end region was computed by the program BEND [3] which uses a 2 dimensional strip along a path that minimizes its strain energy. The cable is stacked to the strip and subsequent tums placed adjacent to each other to form a continuous block (Fig. 1). A magnetic field analysis was used iteratively to determine the final position of the spacers between blocks.

* This work was supported by the Director, Office of Energy Research, Office of High Energy and Nuclear Physics. High Energy Physics Division, U.S. Department of Energy under Contract No. DE-AC03$76 \mathrm{SF} 00098$.

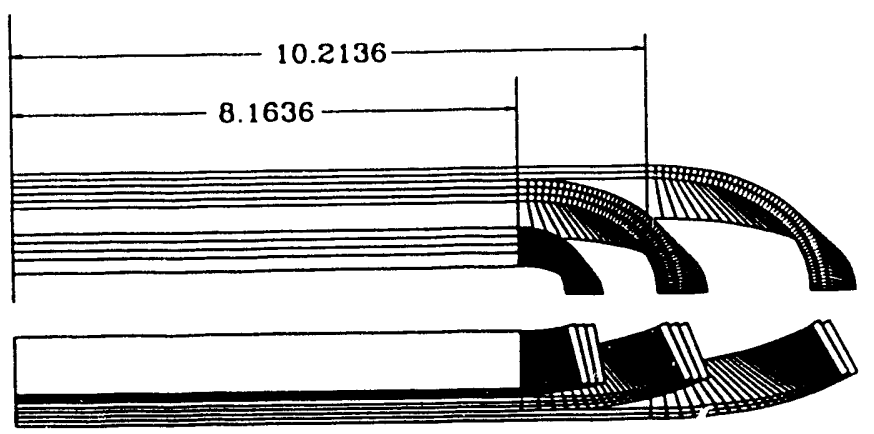

Inner Layer

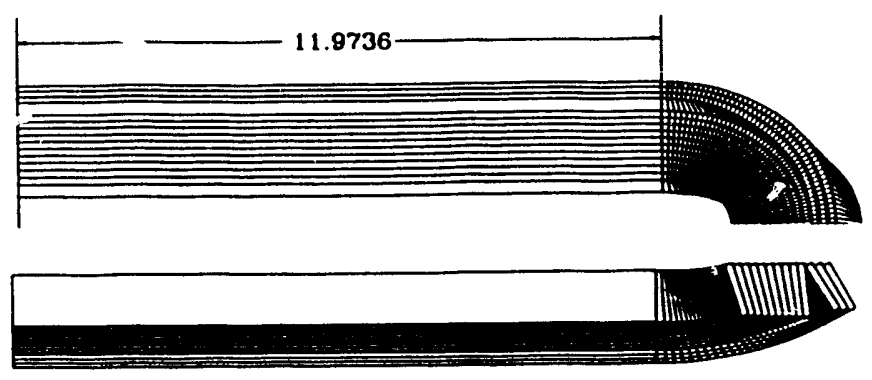

Outer Layer

Fig. 1. Top and side view of windings at the end of the SSC quad.
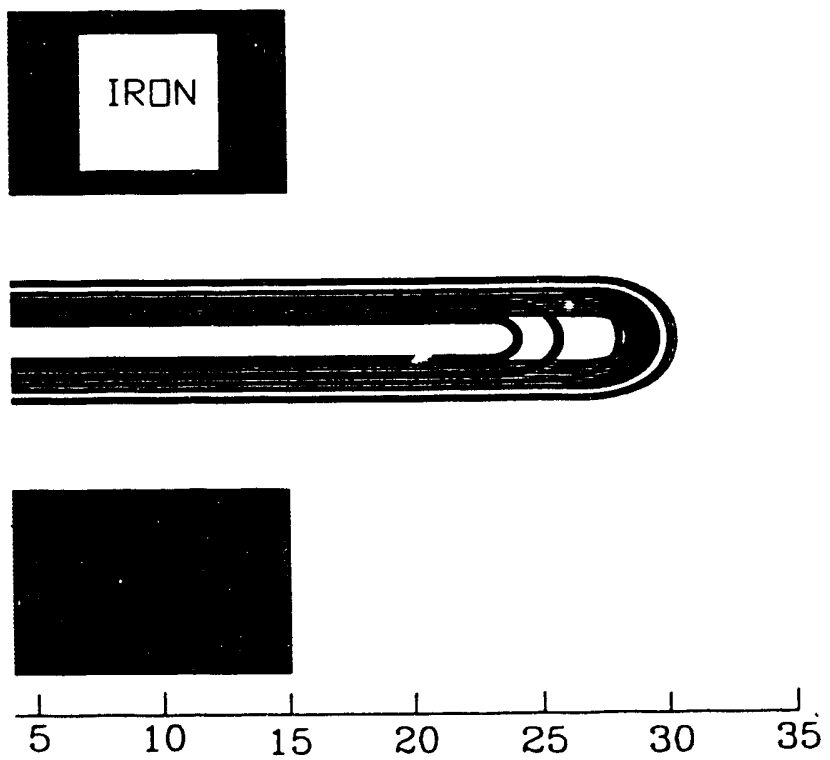

Fig. 2 Schematic of conductor and iron in the end region.

In calculating the magnetic field the cable geometry, as shown in Fig. 1, was used directly. Each element of cable, described as 8 nodes, was used to generate line-current at strand location, or at an equivalent set of Gaussian points that were subsequently used by a Biot-Savart law to calculate the 
magnetic field. We employed 50 elements per tum and 30 strands per element as line currents when the field at the conductor was computed, and a reduced number of 16 Gaussian points per element when hrmonics were computed. In ail cases an axisymmetric high permeability iron was assumed (Fig. 2).

\section{FIELD AT THE CONDUCTOR}

In the 2D section the high field point is located in the inner layer along the pole turn. A 3D search for the high field was carried out on the same turn starting in the 2D section and terminating at the magnet end overpass. Marking location on the cable by strand number and axial distance, field points were calculated with and without iron as shown in Fig. 3. The iron contribution in the straight section is $8.6 \%$ with a maximum field of $5.03 \mathrm{~T}$ (strand 9). At the magnet overpass the iron contribution is negligible, however, the field reaches its maximum value of $5.085 \mathrm{~T}$ (strand 11 ). Care should therefore be taken, if in the future, modifications of the iron are considered near the end.

\section{HARMONICS}

The "end" was designed to produce low integrated harmonics. Initial computations were made simulating each turn as a single line-current placed at its center. The integrated multipole coefficients were derived from an analytical expression similar to the one used in pure 2D computations where only the $z$ directed current is used [4]. Conductor blocks were axially translated until a low set of integrated multipole values were achieved (no iron was used). When iron is not present, the physical length of the "end" starts at the termination of the 2D cross-section $(23.16 \mathrm{~cm})$ and its magnetic length is $4.06 \mathrm{~cm}$, over which the same gradient as the straight section is assumed. The average multipoles $n=6$ and $n=10$, are 2.2 units and 1.5 units, respectively.

Next, we have expressed the 3D field in the "end" in terms of local harmonics where each harmonic is written as a function of $r$ and $z$ [5]. As a result the 2D multipole coefficients $b_{n}$ are replaced by the functions $g_{m}(r, z)$, etc. The g's can be replaced by the expression below, determined only by a set of functions $A_{n}(z)$. Once the $A$ 's are computed the 3 field components can easily be derived.

$$
\begin{gathered}
B_{r}=\sum_{n} g_{r r} r^{n-1} \sin n \theta \\
B_{\theta}=\sum_{z}^{n} g_{\theta r} r^{n-1} \cos n \theta \\
B_{z}=\sum_{n}^{n} g_{m} r^{n} \sin n \theta \\
g_{r n}(r, z)=-n A_{n}(z)+\frac{n+2}{4(n+!)} A_{n}^{\prime \prime}(z) r^{2} \ldots \\
g_{q n}(r, z)=-n A_{n}(z)+\frac{n}{4(n+1)} A_{n}^{\prime \prime}(z) r^{2} \ldots \\
g_{z n}(r, z)=-n A_{n}^{\prime}(z)+\frac{1}{4(n+1)} A_{n}^{m \prime}(z) r^{2} \ldots
\end{gathered}
$$

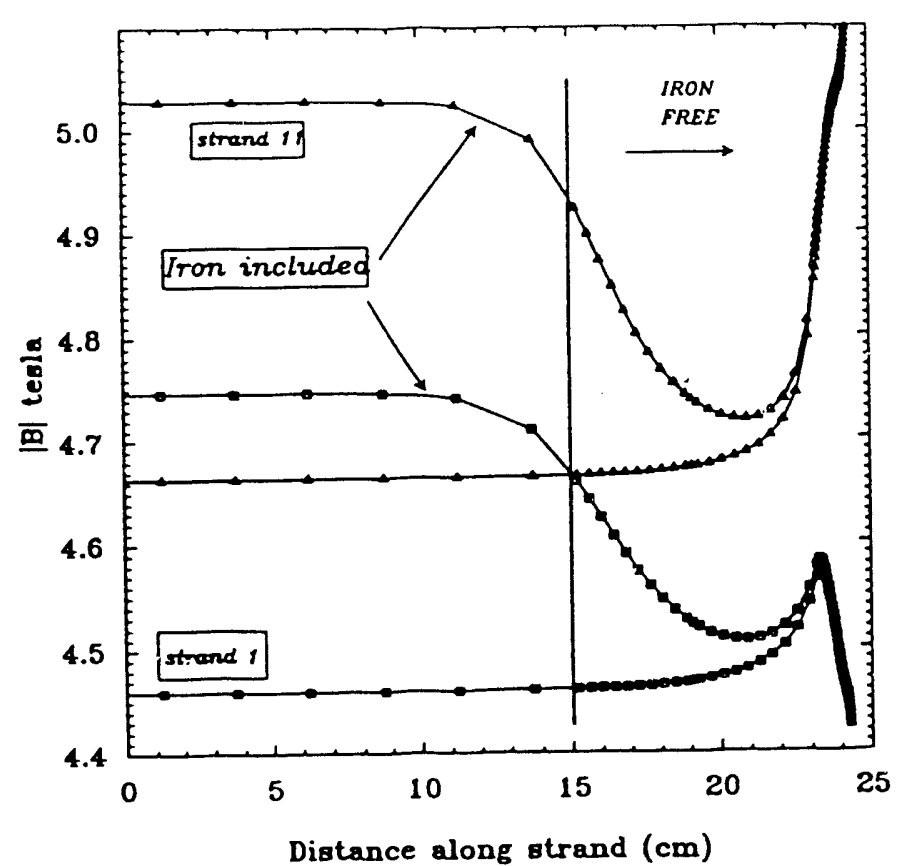

Fig. 3. Absolute field along innermost edge (strandl) and mid cable (strand11) computed on the pole turn of the inner layer.

Note that the g's will reduce to the $2 D$ coefficients $b_{n}$ in the limiting case where $A_{n}(z)$ is not a function of $z$. (the $2 D$ case). The $A$ values and several derivatives have been computed, for the case where both condictor and iron are present, for $n=2,6,10$ and 14 . Plotted here is only the first term in the expressions for $g_{m}$ and $g_{\theta_{n}}$ (Fig. 4).

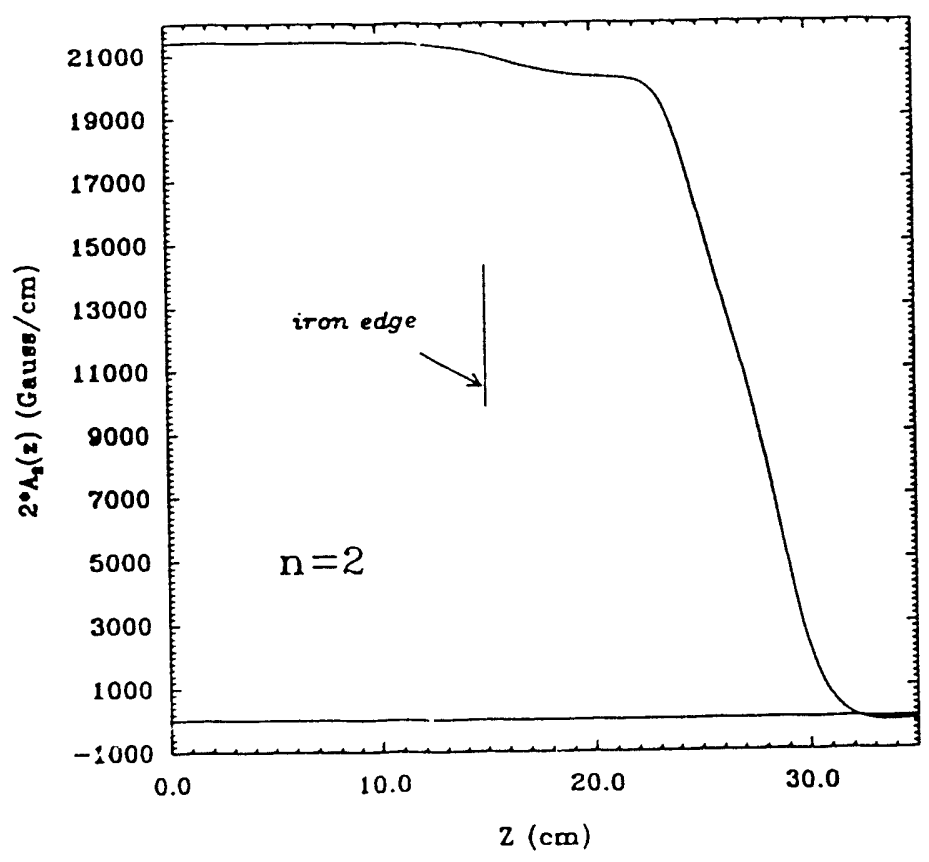



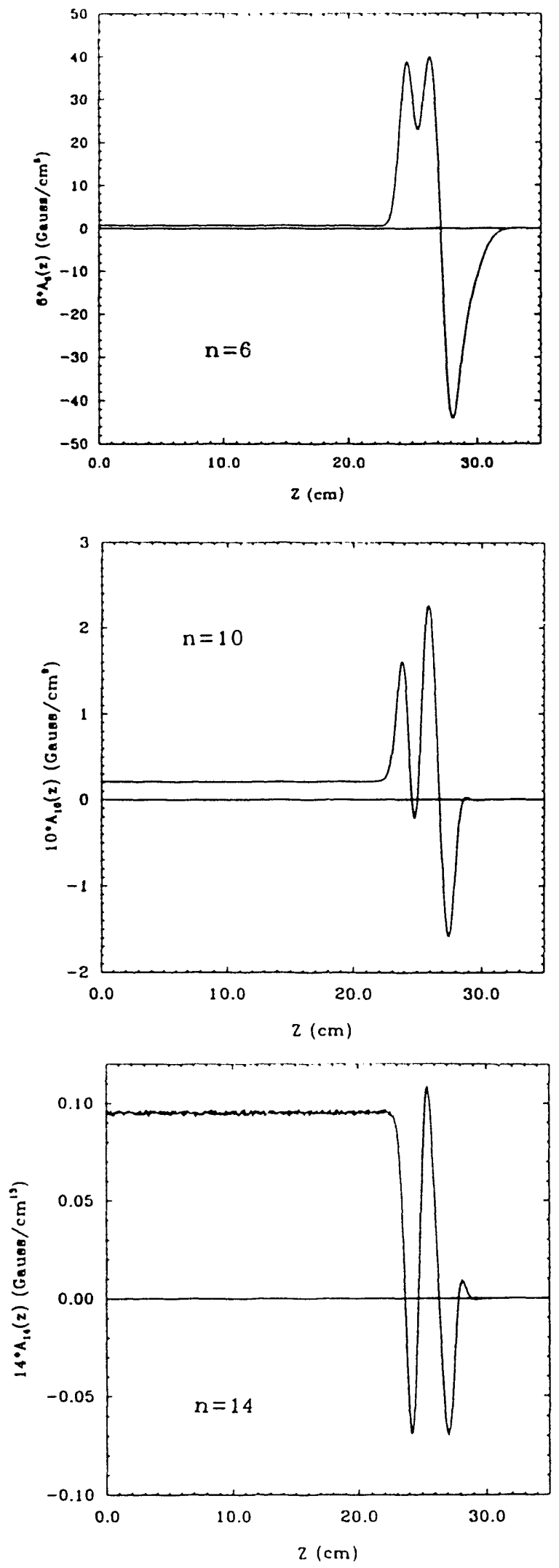

Fig. 4. The first term $n \times A_{n}(z)$ for $n=2,6,10$, and 14 used in the equations for the $g$ 's.
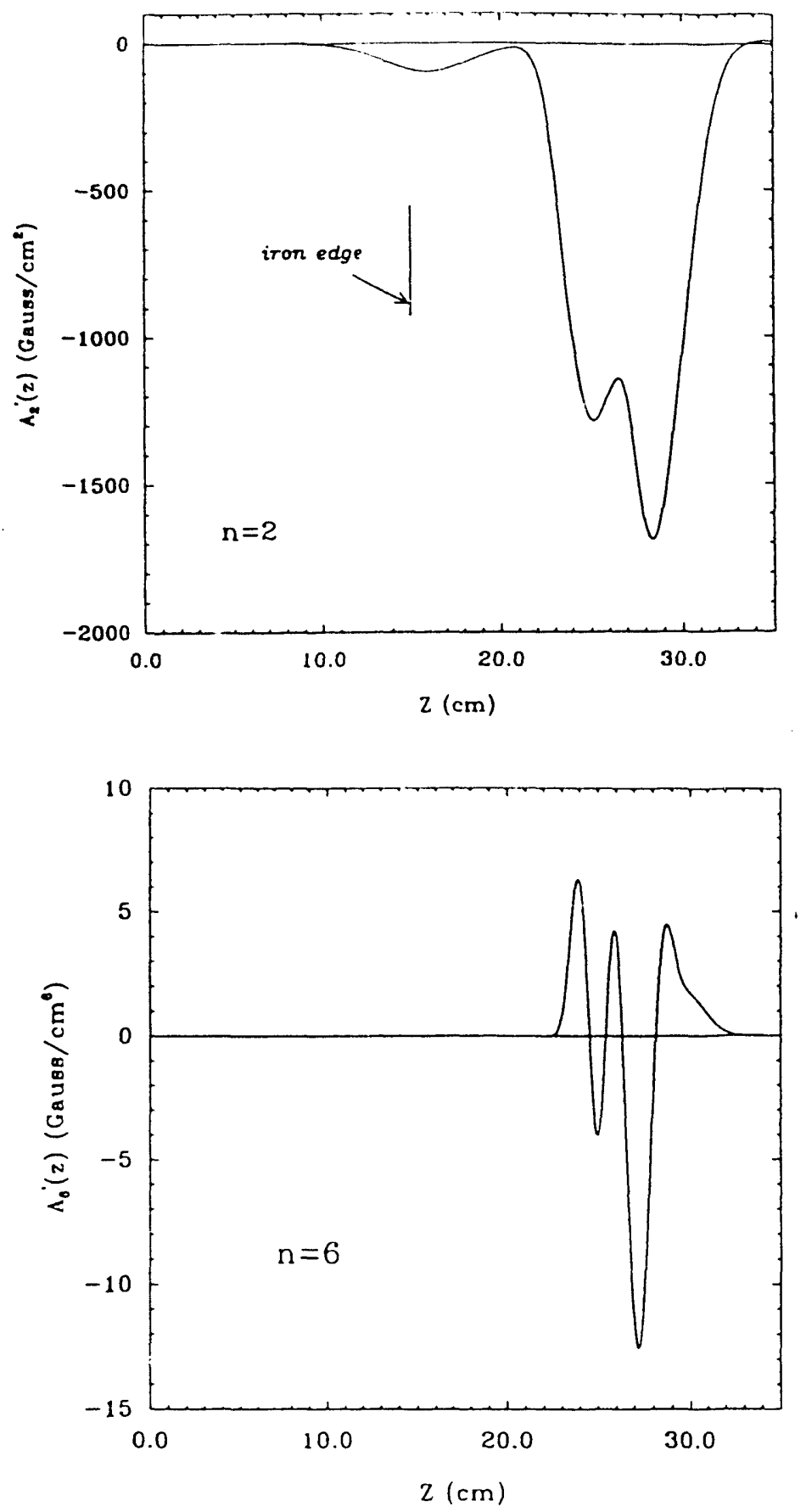

Fig. 5. $A_{n}^{\prime}(z)$ for $n=2$ and 6 .

In Fig. 5 the first derivatives of $A_{2}$ and of $A_{6}$, which correspond to the fundamentai term of the $\mathrm{z}$ directed field $\mathrm{Bz}$, are plotted .

We have integrated the $A$ 's in order to determined magnetic length and multipoles at the "end". Assuming the $2 \mathrm{D}$ cross section terminates at the same location as the iron $(z=15 \mathrm{~cm})$, the "end" magnetic length is $11.45 \mathrm{~cm}$, its gradient is $214.2 \mathrm{~T} / \mathrm{m}$ (same as in the 2D) and its multipoles are 1.54 units for $n=6$ and 1.07 units for $n=10$. The effect of the iron on these values is negligible. 


\section{MEASUREMENTS}

We have built and tested 3 short $(1 \mathrm{~m})$ SSC quads $\mathrm{OC}$ 1,2 , and 3 , and one long magnet $(5 \mathrm{~m}) \mathrm{QCC}-401$. The table below lists the transfer function and allowed harmonics as measured in the straight section of the magnet.

\begin{tabular}{|l|c|c|c|c|}
\cline { 2 - 5 } \multicolumn{1}{c|}{} & \multicolumn{2}{c|}{ Table 1a } \\
\hline \multicolumn{1}{c|}{$\begin{array}{c}\text { Multipole } \\
\text { (1cm) units }\end{array}$} & $\begin{array}{c}\text { Warm } \\
20 \mathrm{~A}\end{array}$ & $\begin{array}{c}\text { Cold } \\
3045 \mathrm{~A}\end{array}$ & $\begin{array}{c}\text { Warm } \\
20 \mathrm{~A}\end{array}$ & $\begin{array}{c}\text { Cold } \\
3042 \mathrm{~A}\end{array}$ \\
\hline Gradient & & & & \\
(T/m-kA) & 32.17 & 32.01 & 32.87 & 32.20 \\
b6-dodecapole & 0.07 & -0.42 & -0.18 & -0.6 \\
b $_{10}$ & 0.01 & 0.11 & 0.05 & 0.06 \\
\hline
\end{tabular}

Table $1 b$

\begin{tabular}{|l|c|c|c|}
\cline { 2 - 4 } \multicolumn{1}{c|}{} & \multicolumn{2}{c|}{ QC-3 } & QCC-401 \\
\hline Multipole & Warm & Cold & Warm \\
(1cm) units & $20 \mathrm{~A}$ & $3055 \mathrm{~A}$ & $20 \mathrm{~A}$ \\
\hline Gradient & & & \\
(T/m-kA) & 32.54 & 32.74 & 32.53 \\
b6-dodecapole & -2.16 & -2.29 & -3.21 \\
b $10^{10}$ & 0.16 & 0.16 & 0.20 \\
\hline
\end{tabular}

During construction, the iron length was terminated $2.5 \mathrm{~cm}$ shorter than the original design, extending the length of the "end" by the same amount. The magnetic length of the non lead end measured in QC-2 is $13.5 \mathrm{~cm}$, with the same gradient as the straight section and a dodecapable of 1.2 units $n=6$ and 0.19 units $n=10$.

\section{REFERENCES}

[1] "The 40mm SSC Arc Quadrupole - Magnetic Design," S. Caspi, Lawrence Berkeley Laboratory note SC-MAG-314, LBID-1677. Nov. 1990.

[2] "Quedrupole Magnets for the SSC Collider," C. E. Taylor, a al, paper presented at the 12 th Intemational Conference on Magnet Technology, Leningrad, USSR. June 24-28, 1991.

[3] "An Application of Differential Geometry to SSC Coil End Dexign," J. M. Cook, SSCL-N-720, Fermilab TM-1663, 1990.

[4] An Integrated Harmonic Analysis for Magnet Ends Including Iron," S. Caspi, M. Helm, and LJ. Laslet, LBID-1560, SC-MAG271, 1988.

[5] "Magnetic Field in the SSC Arc Quad," S. Caspi, M. Helm, and LJ. Laslet, LBL-30668, SC-MAG-336, April 1991. 

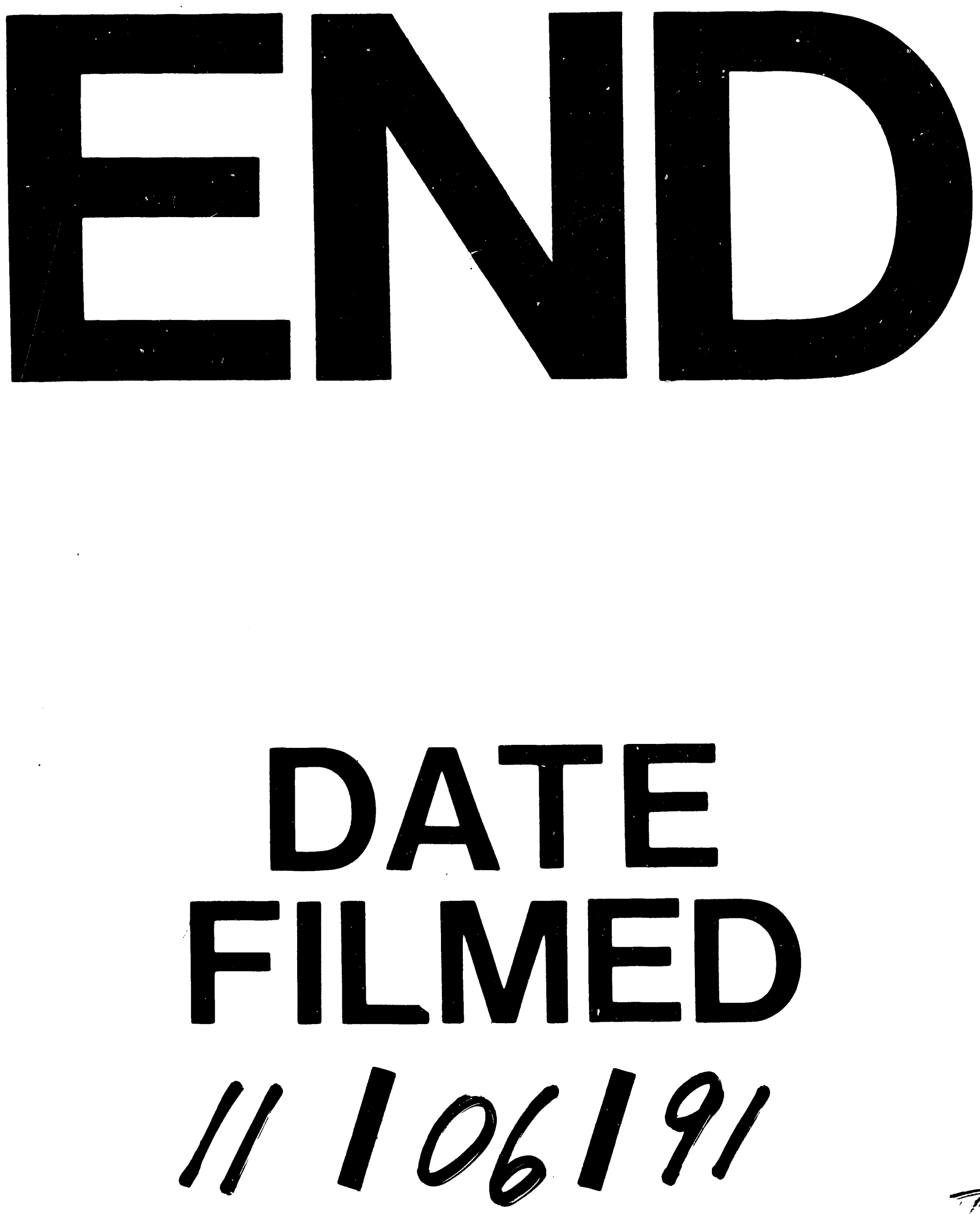
